\title{
NUMERICAL MODELING OF COASTAL TSUNAMI IMPACT DISSIPATION AND IMPACT
}

\author{
Stéphan T. Grilli ${ }^{1}$, Jeffrey C. Harris ${ }^{1}$, Fengyan Shi ${ }^{2}$, James T. Kirby ${ }^{2}$, Tayebeh S. Tajalli \\ Bakhsh $^{1}$, Elise Estibals ${ }^{3}$ and Babak Tehranirad ${ }^{2}$
}

\begin{abstract}
Recent observations of the coastal impact of large tsunamis (e.g., Indian Ocean 2004; Tohoku 2011) and related numerical and theoretical works have made it increasingly clear that tsunami waves arrive nearshore as a series of long waves (so-called N-waves) with, often, the superposition of undular bores around each crest. Such wave trains are much more complex and very much in contrast with the solitary wave paradigm which for a long time was the accepted idealization of tsunami waves in both experimental and numerical work. The dissipation associated with these breaking bores can be very large, particularly over a wide and shallow continental shelf such as along the east coast of North America, particularly for the shorter waves associated with tsunamis generated by Submarine Mass Failures (SMFs). In this paper, we perform numerical simulations of tsunami coastal impact in the context of both idealized laboratory experiments and several tsunami case studies. We attempt to clarify the key physical processes at play in such cases, and discuss the parameterization of long wave dissipation and implications for models of coastal tsunami hazard assessment.
\end{abstract}

Keywords: tsunami modeling; coastal tsunami hazard; submarine mass failure; wave breaking; undular bore

\section{INTRODUCTION}

Correctly assessing coastal tsunami hazard requires accurately modeling the shoaling and breaking of complex wave trains over varying bathymetry/topography, including both the interplay and effects on maximum wave elevation and coastal inundation of nonlinear, dispersive, and breaking dissipation processes. This has become even more evident in light of recent observations of the coastal impact of the large Indian Ocean 2004 and Tohoku 2011 tsunamis (e.g., Grilli et al., 2007; Ioualalen et al., 2007; Grilli et al., 2012) and related numerical and theoretical works have made it increasingly clear that tsunami waves arrive nearshore as a series of long waves (so-called $\mathrm{N}$-waves) with, often, the superposition of undular bores around each crest. Such wave trains are much more complex and very much in contrast with the solitary wave paradigm which for a long time was the accepted idealization of tsunami waves in both experimental and numerical work.

Long wave models that include all of these processes up to some degree (so-called extended and fully nonlinear Boussinesq models) have been developed that are now widely used in tsunami modeling. In this respect, the authors are currently developing tsunami inundation maps for the U.S. East Coast, as part of the U.S. National Tsunami Hazard Mitigation Program (NTHMP), using such a model (referred to as FUNWAVE-TVD; Shi et al., 2012; Kirby et al. 2012). Other types of models, the so-called non-hydrostatic long wave models, that more accurately discretize the flow field over depth, have also been used in part of this work (the model used here is referred to as NHWAVE; Ma et al. 2012). While these models all appear adequate to simulate tsunamis from their generation area (i.e., source) to nearshore, up to close to the breaking point, recent work indicates that a more accurate assessment, and possibly parameterization, of energy dissipation in breaking undular bores, which make up tsunami wave trains in the nearshore area, might be required. Traditional breaking criteria and single-bore dissipation models, developed and calibrated for swells or solitary waves, may indeed be inadequate for capturing the complex physics that takes place in such processes.

Tsunamis can be triggered by a variety of geophysical phenomena, including earthquakes and both submarine and subaerial landslides. In the first and more common case, a co-seismic tsunami is caused by the ocean seafloor displacement (uplift and subsidence) resulting from large magnitude earthquakes. As these co-seismic tsunamis have very long wavelengths, they have traditionally been simulated with models based on the nonlinear shallow water equations. For submarine and subaerial landslides, however, the waves produced are shorter and hence more dispersive, so non-hydrostatic models such as Boussinesq models have been used (Watts et al., 2003).

As indicated above, traditionally, solitary waves have been used as idealized examples of tsunamis in theoretical and numerical models. This has been discussed by Madsen et al. (2008), who also showed that tsunamis are often not analogous to solitary waves. Instead, field observations show that most tsunamis approach the shoreline as leading elevation or depression waves, which ultimately

\footnotetext{
${ }^{1}$ Department of Ocean Engineering, University of Rhode Island, Narragansett, RI 02882, USA

${ }^{2}$ Center for Applied Coastal Research, University of Delaware, Newark, DE 19716, USA

${ }^{3}$ ENSEIRB-MATMECA, University of Bordeaux 1, 33402 Talence Cedex, France
} 
COASTAL ENGINEERING 2012

steepen and, as dispersive effects become gradually more important near the coast, split into a series of shorter waves. As these short waves eventually break, Madsen et al. also suggested that the amount of dissipation may not affect the overall coastal tsunami impact very much, since as the shorter waves are removed, the bulk of the long-wave tsunami is still causing the majority of inundation and runup.

In this paper, we present a number of examples illustrating the issues involved with coastal tsunami impact when dispersive effects cause the appearance of undular bores, including the tsunami caused by the potential flank collapse of the Cumbre Vieja Volcano (CVV; e.g., Ward and Day 2001; Lovholt et al. 2008; Abadie et al. 2012), laboratory experiments of breaking undular bores (Matsuyama et al. 2007), the 1998 landslide tsunami of Papua New Guinea (Tappin et al. 1998), and the Currituck landslide tsunami (Geist et al. 2009). We attempt to both understand and clarify the key physical processes at play in such cases, and discuss the parameterization of long wave dissipation and implications for models of coastal tsunami hazard assessment.

\section{METHODOLOGY}

This study makes use of both a fully nonlinear and dispersive Boussinesq long wave model FUNWAVE-TVD (Kirby et al. 2012; Shi et al. 2012) and the non-hydrostatic three-dimensional (sigma-layer) model NHWAVE (Ma et al. 2012), to generate and propagate tsunamis towards shore. Tsunamis are generated several ways. For the CVV case study, we use the three-dimensional source developed by Abadie et al. (2012). For the Currituck submarine landslide we model the slide as a rigid body with elliptical footprint and Gaussian shape (Enet and Grilli 2007), moving as a translational slide; slide motion is specified as a bottom boundary condition in NHWAVE to generate the initial tsunami source. For both cases, the tsunami source is interpolated as a hot start (both surface elevation and horizontal velocity) into the FUNWAVE-TVD grid to proceed with simulations of nearshore propagation and run-up. Finally, for the one-dimensional laboratory case, we simply initialize FUNWAVE-TVD using the measured waveform.

\section{FUNWAVE-TVD Model}

FUNWAVE-TVD was implemented in both Cartesian (Shi et al. 2012) and spherical (Kirby et al. 2012) coordinates, using the MPI (Message Passing Interface) environment, to be efficient when run on parallel computer clusters. This model solves the fully nonlinear and weakly dispersive Boussinesq equations of Chen et al. (2000) and has been validated against a wide range of benchmark problems (Tehranirad et al. 2011). Unlike the earlier finite-difference implementation of FUNWAVE based on Wei et al.'s (1995) and Wei and Kirby's (1995) equations, the present model makes used of a finitevolume, high-order, total variation diminishing (TVD) scheme. This TVD scheme ensures that nonphysical instabilities that could appear as high-frequency oscillations do not develop in the simulation results. In earlier versions of FUNWAVE, the finite difference approach resulted in instabilities that needed to be filtered out every few time steps. The advantages of such a TVD approach for tsunami modeling, when dealing with sharp surface gradients, has been noted in other models as well (e.g., Lynett and Liu, 2008).

Wave breaking is modeled, similar to Tonelli and Petti (2009): during simulations, when the local surface elevation to depth ratio exceeds a constant breaking criterion (typically 0.8 ), wave breaking is assumed to be occurring and the model Boussinesq equations are switched to the nonlinear shallow water equations by turning off the dispersive terms. Earlier work shows that the TVD shock-capturing dissipative numerical algorithm provides the correct physical dissipation for breaking solitary waves (as benchmarked; i.e., Tehranirad et al. 2011). This however may not be true for more complex flows, and shall be investigated in this work.

\section{NHWAVE Model}

In order to model a submarine landslide tsunami, the non-hydrostatic wave model NHWAVE (Ma et al. 2012) provides a numerical solution to the three-dimensional Navier-Stokes equations for incompressible flow (actually since viscosity is neglected, one actually solves Euler equations). This model has the capability to deal with moving seabeds, which is necessary for specifying the motion of submarine landslides and FUNWAVE-TVD does not yet have in its present implementation. NHWAVE uses the analytical equations of motion developed by Grilli and Watts (2005) for rigid slides or slumps to impose the time-varying changes to the initial bathymetry due to a submarine landslide. Ma et al. (2012) have validated the model against the laboratory experiments of Enet and Grilli (2007) for tsunami produced by rigid underwater landslides. 


\section{APPLICATIONS}

Far-field Impact of the Cumbre Vieja Volcano Flank Collapse on the US East coast

Since the pioneering work of Ward and Day (2001), many studies have considered the potential near- and far-field effects of a flank collapse of the Cumbre Vieja Volcano (CVV) in La Palma (Canary Islands; e.g., Pérignon 2006; Løvholt et al. 2008; Abadie et al. 2009, 2011, 2012). In general, these works simulated the tsunami that would result from a subaerial landslide with a volume of $500 \mathrm{~km}^{3}$, that Ward and Day had used as the extreme possible scenario and predicted could cause 10 to 25 meters of flow depth along the U.S. East Coast. More recent work based on slope stability analysis showed that the likeliest volume for such an event would be significantly smaller (about $80 \mathrm{~km}^{3}$ ), and even for an extreme (very low return period) slide scenario $\left(450 \mathrm{~km}^{3}\right)$, the resulting far-field waves along the US East Coast would be nearly order of magnitude smaller (Abadie et al. 2012; Harris et al. 2012).

\begin{tabular}{|c|c|c|c|c|}
\hline Res. & Latitude & Longitude & Sponge (N/E/S/W) & Sim. time \\
\hline $2.0^{\prime}$ & $10.0^{\circ} \mathrm{N}-60.0^{\circ} \mathrm{N}$ & $85.0^{\circ} \mathrm{W}-5.0^{\circ} \mathrm{E}$ & $200 / 200 / 200 / 200 \mathrm{~km}$ & 6h20m \\
\hline $30 "$ & $34.5^{\circ} \mathrm{N}-47.0^{\circ} \mathrm{N}$ & $80.5^{\circ} \mathrm{W}-58.0^{\circ} \mathrm{W}$ & $10 / 150 / 150 / 10$ km & $1 \mathrm{~h} 20 \mathrm{~m}$ \\
\hline $7.5 "$ & $38.0^{\circ} \mathrm{N}-41.0^{\circ} \mathrm{N}$ & $76.0^{\circ} \mathrm{W}-71.0^{\circ} \mathrm{W}$ & $100 / 100 / 100 / 100 \mathrm{~km}$ & $3 \mathrm{~h} 00 \mathrm{~m}$ \\
\hline
\end{tabular}

(a)

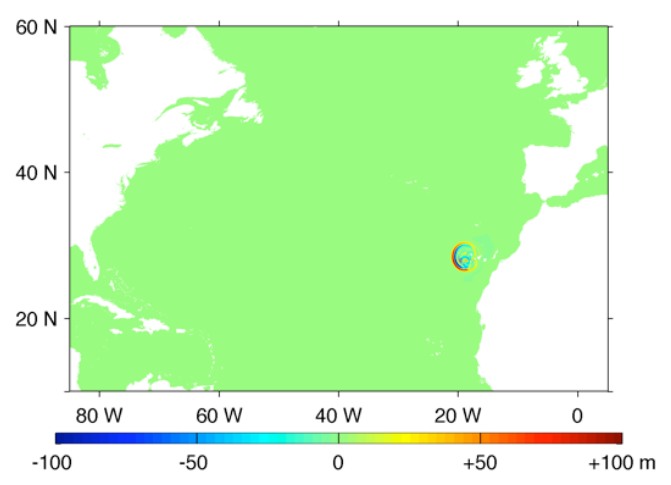

(c)

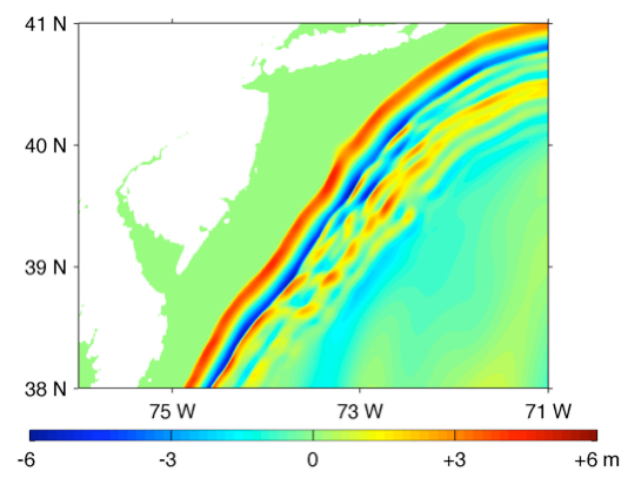

(b)

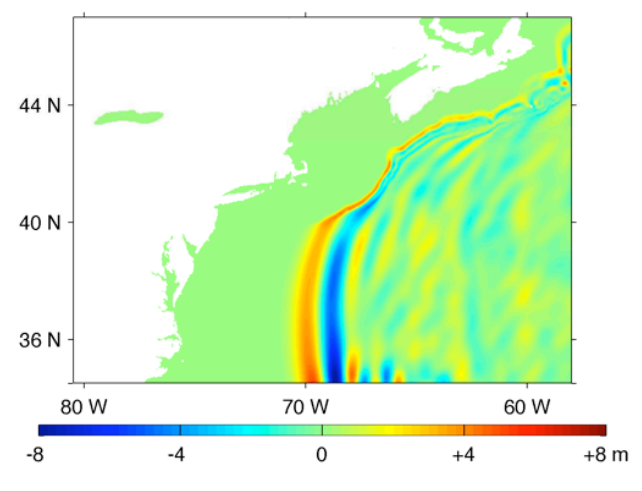

(d)

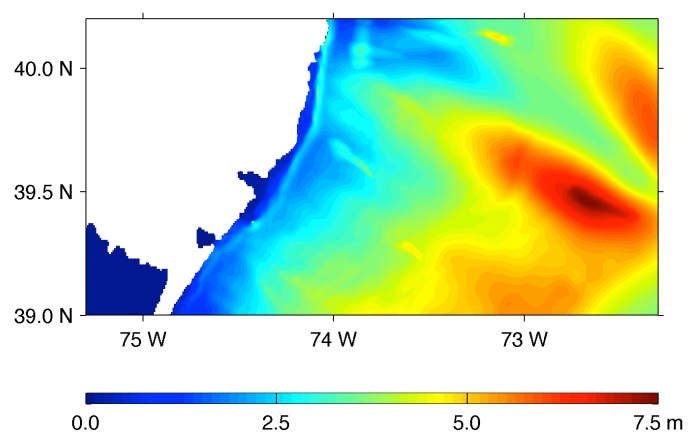

Figure 1. (a) Initial wave elevation from Abadie et al. (2012) for a $450 \mathrm{~km}^{3} \mathrm{CVV}$ landslide, 20 min. after the flank collapse is initiated; (b) Initial wave elevation on 30" grid (from interpolated 2' ocean basin grid results), 6 hours and $40 \mathrm{~min}$. after the flank collapse is initiated; (c) Initial wave elevation on 7.5" grid (from interpolated 30" grid results), 8 hours after the flank collapse is initiated; (d) Maximum wave elevation (of all grids) at 7.5 " resolution (or about $220 \mathrm{~m}$ ).

Using the subaerial tsunami source developed by Abadie et al. (2012) as an initial condition, we consider here the results of simulating the far-field tsunami propagation with FUNWAVE-TVD, in three nested grids with resolutions of 2 arc-min, 30 arc-sec, and 7.5 arc-sec (Fig. 1). Table 1 shows the size, location, sponge layer widths, and simulation time for each grid, and Fig. 1 shows instantaneous 
surface elevations computed for a series of times. (This particular set of grids focuses on New Jersey, which includes Atlantic City, one of the locations of detailed tsunami inundation performed for the NTHMP project.) The initial surface elevation and velocity field for the 2 arc-minute grid is obtained from Abadie et al.'s (2012) three-dimensional subaerial landslide solution for a $450 \mathrm{~km}^{3}$ volcano collapse, $20 \mathrm{~min}$. after the flank collapse is triggered. Subsequent surface elevations and velocities are obtained by interpolating results from the preceding coarser resolution grid.

It is remarkable that while the maximum wave elevation offshore is around $7 \mathrm{~m}$ (Fig. 1d), indicating a wave height nearly double, near the shoreline the maximum elevation computed in the last but still fairly coarse resolution grid (about $220 \mathrm{~m}$ ) is only about $1 \mathrm{~m}$. While this large predicted decay/dissipation of incident tsunami waves may be affected by grid resolution, the 7.5" grid should certainly be fine enough to resolve such incident long wave trains propagating over the continental shelf. Hence, without further analysis, these results would suggest that coastlines such as this part of the US East Coast, with wide, shallow continental shelves are well-protected against the somewhat shorter wavelength long waves that are characteristics of landslide tsunamis, because of the intense breaking dissipation over the wide shelf. However, we know from observations of recent tsunamis and other work (e.g., Madsen et al., 2008) that long incident waves develop into undular bores made of much shorter waves during their propagation over the shelf and shorter waves in these bores will break and dissipate significantly before reaching the shoreline, but still pose a significant coastal hazard. Hence, the model grid (and equations) should accurately resolve these phenomena to properly model coastal tsunami impact, which may not be true in the 7.5 " grid. Therefore, because of the intense dissipation of incident waves seen here and as the exact dissipation rate of breaking bores may not be well modeled at this resolution, we consider other cases in the following before deciding whether the coastal hazard from an extreme CVV event is negligible.

Comparison of Wave Fission Results with Laboratory Tests

Matsuyama et al. (2007) conducted experiments of tsunami shoaling over a shelf that was setup in a $205 \mathrm{~m}$ long two-dimensional wave flume (Fig. 2). The setup consisted of a $4.0 \mathrm{~m}$ deep region, followed by a $1 / 10$ slope; from the depth of $0.45 \mathrm{~m}$ to the shoreline a $1 / 200$ slope corresponded to a typical continental shelf. On such mild slopes in shallow water, dispersion causes an initial long wave generated in the tank to split into undular bores made of many soliton-like shorter waves that propagate toward the shoreline, while "riding" the underlying longer wave, and eventually individually break. Because of the similarity with recent observations of large tsunamis and recent model simulations such as discussed above, these experiments allow for a validation of FUNWAVE-TVD's ability to accurately model the propagation, transformation, and breaking for this type of wave.

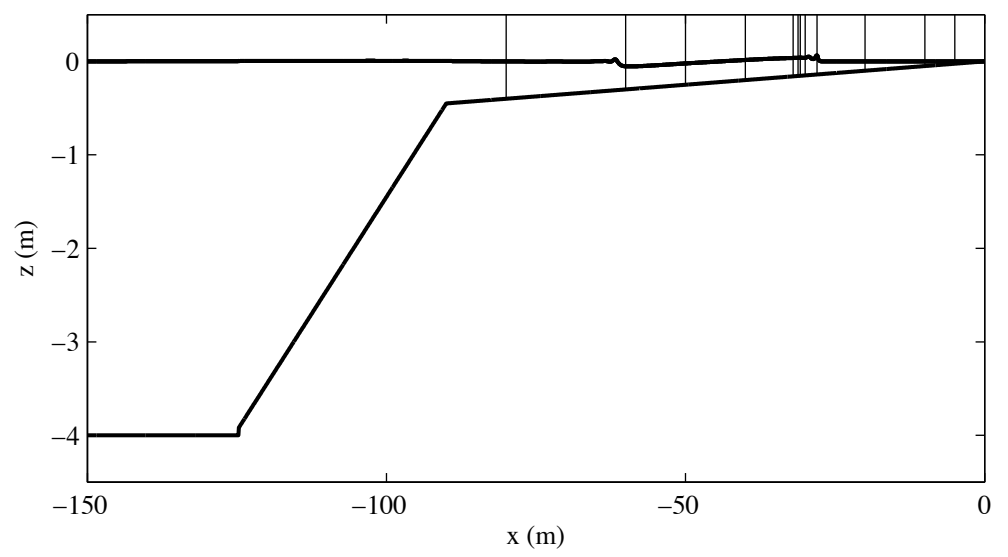

Figure 2. Wave flume setup of Matsuyama et al.'s (2007) experiments for a 1/200 upper shelf slope. Vertical lines indicate locations of wave gages.

In experiments, an initial wave profile corresponding to a single cycle of a sinusoid was generated in the tank. For Matsuyama et al.'s test 024, which we model here, this wave has a period of $T=20 \mathrm{~s}$ and an amplitude of $0.3 \mathrm{~m}$. The one-dimensional FUNWAVE-TVD grid had 2400 cells, with a grid spacing of $8.3 \mathrm{~cm}$, over the entire length of the tank. 
Fig. 3 shows that FUNWAVE-TVD qualitatively reproduces the observed wave features, including the increasing wave height and decreasing wavelength during shoaling and the fission into an undular bore made of soliton-like waves, as the wavetrain approached the shore (compare with Matsuyama et al.'s Fig. 5). The general shape and number of solitons formed also agree quite well with observations. The maximum predicted wave elevation offshore, however, is only $7.2 \mathrm{~cm}$ at breaking by contrast with the observed breaking height of $14 \mathrm{~cm}$. This under-prediction in wave height suggests that the shoaling and breaking of the shorter soliton-like waves may have been under-resolved in these simulations.
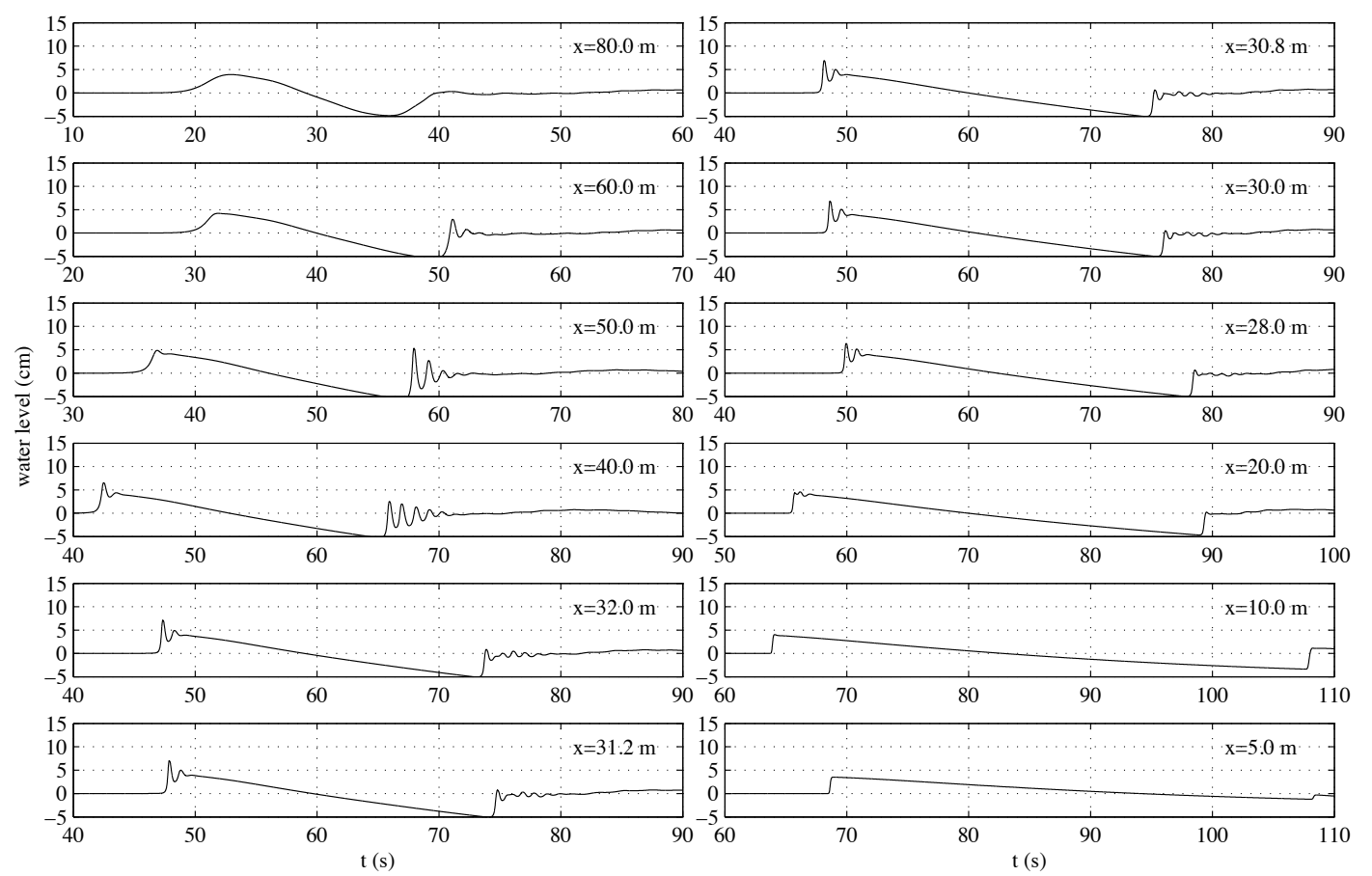

Figure 3. FUNWAVE-TVD simulation of time series of surface elevation for wave gages used in Matsuyama et al. (2007) experiments (Fig. 2; see their Fig. 5); the incident wave period is $20 \mathrm{~s}$, and amplitude is $3 \mathrm{~cm}$.

Kim and Lynett (2011) also used a Boussinesq wave model (BM) to simulate these laboratory experiments and showed a similar good agreement with Matsuyama's results, using a similar discretization (their grid spacing was $7.5 \mathrm{~cm}$ ). As in our results, while they simulated the observed waveforms quite well, they underpredicted the breaking wave elevation. Interestingly, they also compared their model results to those of the nonlinear shallow water equations (NSW), with the laboratory observations as a reference. Although the predicted shape of waves significantly differ in NSW results, with the absence in particular of the undular bores, they show that runup is essentially identical for BM and NSW results and, hence, is not significantly affected by the highly dispersive undular bores. This behavior was also pointed out by Madsen et al. (2008), where the soliton fission and wave breaking of the shorter waves had little effect on the main long wave of the tsunami and its eventual coastal runup.

The relative change in wave elevation from offshore to the coast in these experiments can be qualitatively compared with our results for the CVV case. In Matsuyama et al.'s experiments, incident waves had a $5 \mathrm{~cm}$ height offshore and waves broke around a $14 \mathrm{~cm}$ height, and then ended up with a height of only $2 \mathrm{~cm}$ at the wave gage closest to shore. Although viscous dissipation tends to be overestimated in small-scale laboratory experiments, these results indicate that very large dissipation over a mildly sloping shelf, such as seen in the previously discussed CVV case, may be physically possible. One significant difference though is that here there is a leading elevation wave, whereas for a submarine landslide there usually is a leading depression wave.

\section{Papua New Guinea SMF}

The Papua New Guinea (PNG) tsunami of 1998 is generally considered to have been caused by a rotational submarine mass failure (SMF), triggered by the M7.2 earthquake, after a 15 min delay. 
Tappin et al. (2008) provided a detailed review of the PNG modeling work to date and modeled the tsunami using an earlier version of FUNWAVE. Here we briefly revisit the PNG tsunami, by performing both a SMF tsunami generation similar to that of Tappin et al., i.e., using TOPICS (Grilli and Watts, 2005) instead of NHWAVE to model tsunami generation and propagation in a twodimensional grid with $50 \mathrm{~m}$ resolution using FUNWAVE-TVD, and then focusing on high-resolution one-dimensional (1D) transects to finely resolve the waves approaching the coastline (Fig. 4). Thus, after 4.5 min. of simulated time, a 1D transect is selected for the higher-resolution study (Fig. 4).

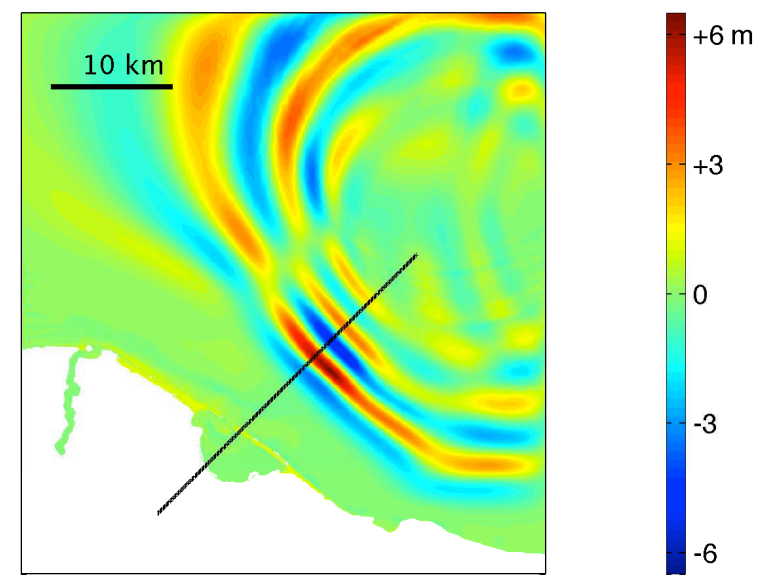

Figure 4. Surface elevation of the PNG landslide tsunami (Tappin et al., 2008) computed in 2D with FUNWAVE-TVD in a $50 \mathrm{~m}$ grid and used to initialize a 1D transect, $4.5 \mathrm{~min}$ into the simulation. TOPICS is used to define the initial condition.

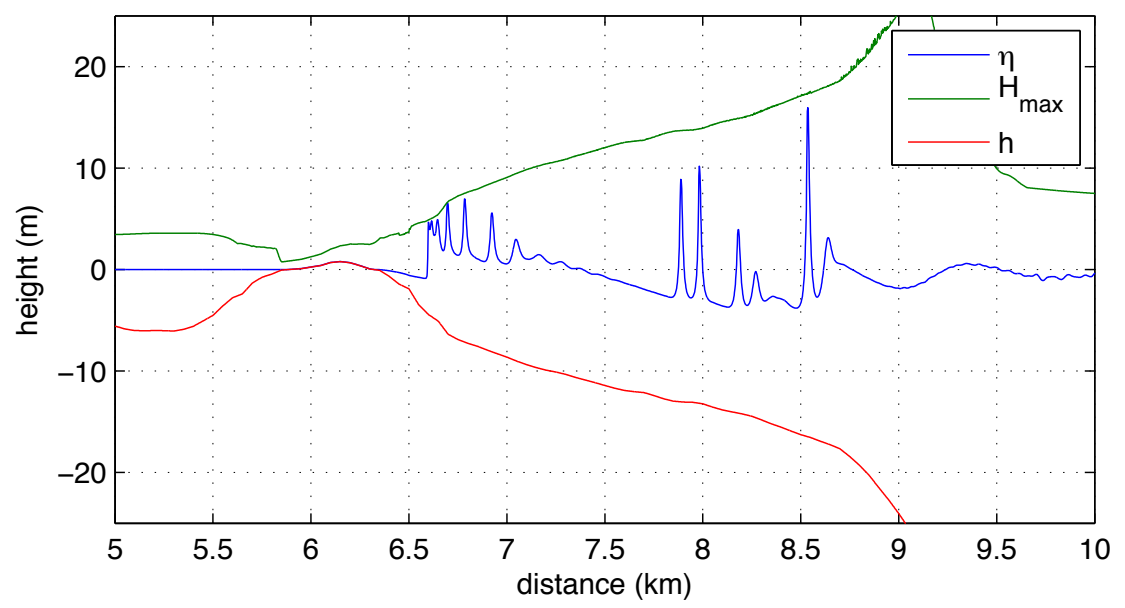

Figure 5. FUNWAVE-TVD simulation of the PNG tsunami (Fig. 4), using a breaking criterion $\kappa=1.05$, along a 1D transect: bathymetry (red line), wave elevation at $350 \mathrm{~s}$ after the 1D simulation starts (blue line), and maximum wave envelope over the course of the simulation (green line).

FUNWAVE-TVD results computed along the 1D transect with a $2 \mathrm{~m}$ horizontal resolution (Fig. 5) show that, shortly after the 1D simulations started, an undular bore yielding soliton-like shorter waves is also created for this tsunami case study. These waves shoal-up and start breaking at about $9.1 \mathrm{~km}$ offshore, with a maximum elevation $\eta_{c b}=23 \mathrm{~m}$ in a $h_{b}=25 \mathrm{~m}$ depth; in these simulations, a breaking criterion $\kappa=H_{b} / h_{b}=1.05$ was used, as found to be relevant from the Boundary Element (BEM) simulations presented next. Wave breaking results in a complex wavetrain as the tsunami approaches the shore, in which the height of the soliton-like shorter waves very strongly decays. The breaking criterion value used in simulations was varied from 0.8 to 1.5 , but while this had large effects on the shorter wave trains seen along the shelf, the coastal impact in terms of flow depth on the Sissano lagoon barrier island (near $6.3 \mathrm{~km}$ ) was nearly independent of the breaking criterion. 
We can further validate the BM results of Fig. 5 by comparing them with those of other more complete models, such as solving fully nonlinear potential flow (FNPF) or Navier-Stokes (NS) equations. Here we first use the 2D-FNPF numerical wavetank of Grilli et al. (1989) and Grilli and Subramanya (1996), which is based on a very accurate Boundary Element Method (BEM), and model wave propagation along the same vertical transect up to the breaking point. While the BEM model solves the full set of FNPF equations and can simulate overturning waves, computations are interrupted when a breaker jet impacts the free surface, so predicting breaking dissipation is not possible in this BM-BEM comparison. Thus, using the same 1D initial conditions, we are able to compare to the FUNWAVE-TVD results obtained with different breaking criteria (Fig. 6). While differences between the $\mathrm{BM}$ and $\mathrm{BEM}$ results are very small prior to breaking, discrepancies increase at breaking (leftward curve in Fig. 6a). BEM results in Fig. 6b, however, confirm that breaking criterion $\kappa=1.05$ is relevant for this case.

(a)

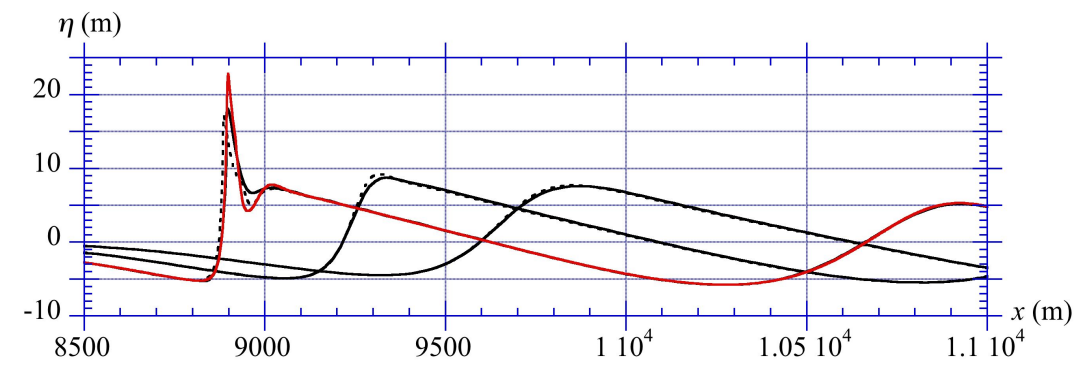

(b)

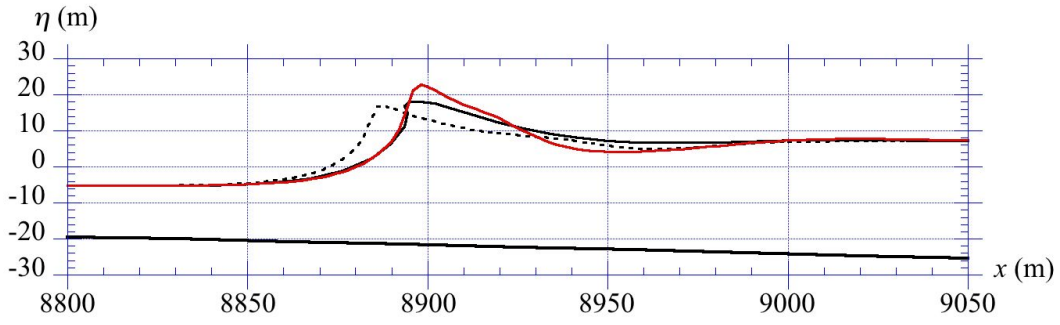

Figure 6. Comparison of FUNWAVE-TVD simulations using a breaking index of $\kappa=0.8$ (black dashed), $\kappa=1.1$ (solid red), and Boundary Element Method (BEM) results (solid black) for three times, $20 \mathrm{~s}$ apart. Fig. (b) shows the same results as in Fig. (a) with an undistorted scale. The BEM model predicts at breaking with $\kappa=$ 1.1 , that $H_{b}=23 \mathrm{~m}$ and $h_{b}=21 \mathrm{~m}$.

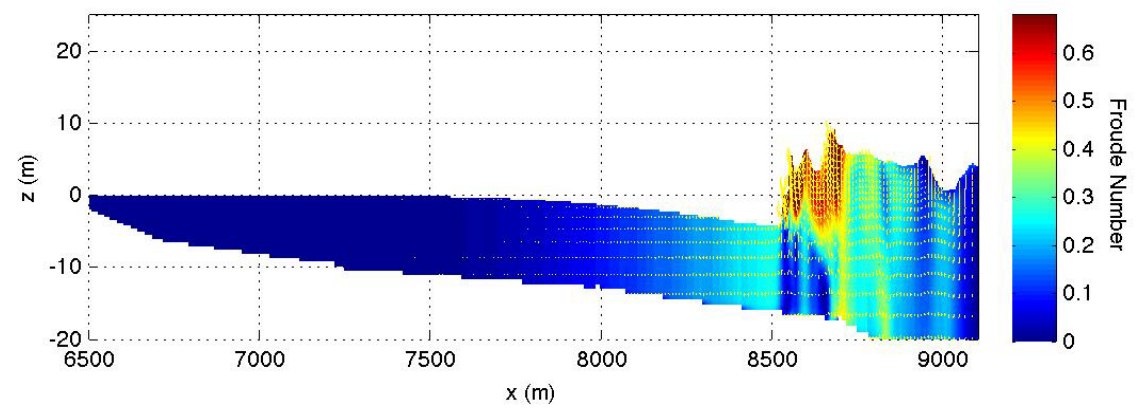

Figure 7. Case of Figs. 5 and 6. NS (MONGOOSE) simulation, $30 \mathrm{~s}$ after wave overturning. Note that the wave is already rapidly decaying, with wave elevations less than $5 \mathrm{~m}$ at the initial crest.

Another obvious candidate for modeling short wavelength incident bores past the breaking point is a NS model, in which we can similarly setup a 1D transect of wave elevation and velocity. Here, we apply the VOF model MONGOOSE (Shi et al. 2004), and analyze the rate of wave dissipation in results. This model uses a grid discretization that is smoothly varied from a grid spacing of $28 \mathrm{~m}$ offshore (at $x=12 \mathrm{~km}$ ) to a grid spacing of $2 \mathrm{~m}$ (at $x=9 \mathrm{~km})$, with a constant $2 \mathrm{~m}$ spacing for all points 
closer to shore. MONGOOSE uses a $k-\varepsilon$ turbulence closure model, which makes it possible simulating waves breaking beyond overturning, which the BEM approach could not do. We see in Fig. 7, however, that the rate of wave dissipation observed in MONGOOSE is much faster than expected from the earlier FUNWAVE-TVD results. We know from field data that flow depth measured along the Sissano barrier shoreline in the area varied between 6 and $15 \mathrm{~m}$, so if waves are less than $5 \mathrm{~m}$ high several $\mathrm{km}$ offshore, the results can be considered as poor. The issue of excessive numerical dissipation in NS solvers for wave flows is well known, which unfortunately means that without a very computationally-intensive setup, such NS results are not able to help solve the breaking dissipation issue.

\begin{tabular}{|c|c|c|c|c|}
\hline & Length $(\mathrm{m})$ & Width $(\mathrm{km})$ & Height $(\mathrm{m})$ & Volume $\left(\mathrm{km}^{3}\right)$ \\
\hline Slide 1 & 18.0 & 8.0 & 750 & 108 \\
\hline Slide 2 & 11.0 & 25.9 & 200 & 57 \\
\hline Composite & 30.0 & 20.0 & 275 & 165 \\
\hline
\end{tabular}

(a)

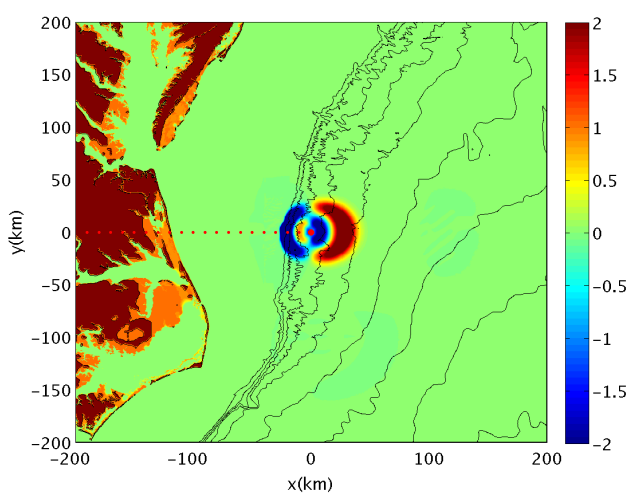

(c)

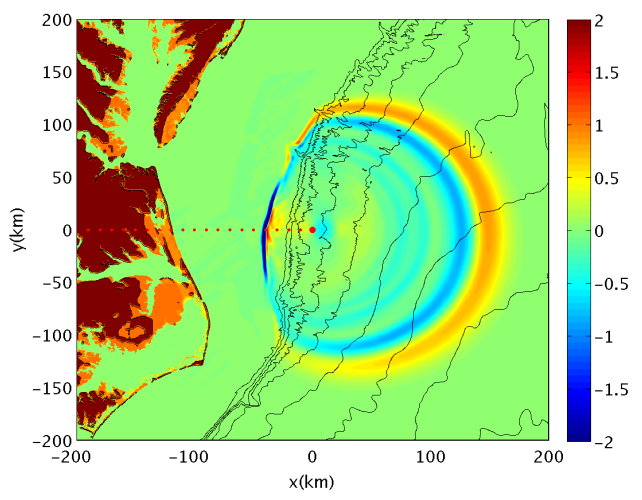

(b)

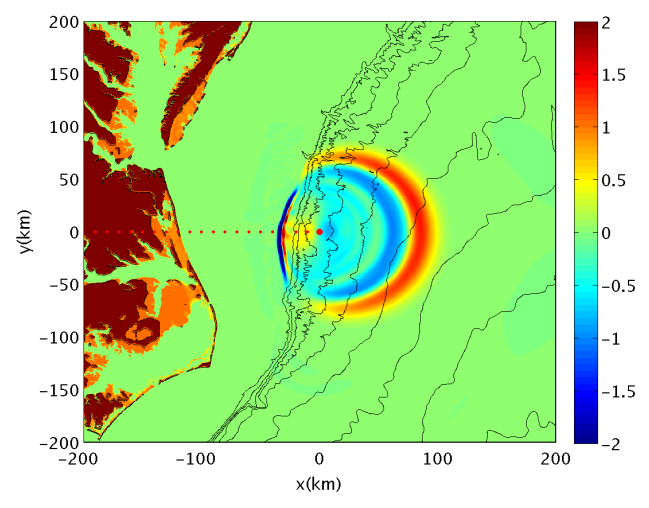

(d)

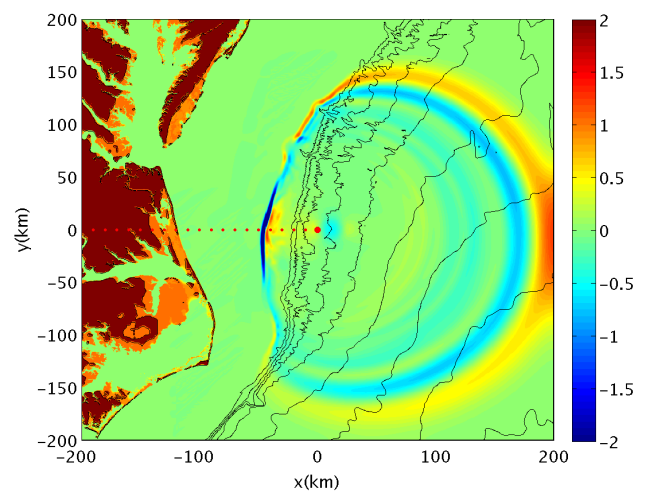

Figure 8. Currituck SMF tsunami simulation in a $500 \mathrm{~m}$ grid. Surface elevation (meters) computed by NHWAVE for the composite slide at (a) $t=180 \mathrm{~s}$; (b) $t=540 \mathrm{~s}$; (c) $t=900 \mathrm{~s}$; (d) $t=1150 \mathrm{~s}$. The dashed red line indicates the location of a 1D transect used for subsequent high-resolution modeling in FUNWAVE-TVD.

Overall, we clearly see from the BEM results that while there are slight errors in FUNWAVE-TVD in the wave evolution near the breaking point, the breaking criterion of 1.05 yields approximately correct results. NS results are able to model waves past the breaking point, but because of the distances involved, the results are too dissipative to be useful. Results for FUNWAVE-TVD vary depending on the breaking criterion chosen, but overall the coastal impact is less than that expected from field data (which of course could also be due to the tsunami source used). Without better results from a second model that can model wave breaking over such a large area, it is useful to consider a similar landslide 
tsunami case where a similar waveform has been simulated with other BM models, so a comparison with FUNWAVE-TVD results can be made, which is shown next.

Undular Bores Generated by Currituck-like Submarine Landslide

The Currituck landslide is a large (approximately $165 \mathrm{~km}^{3}$ ) submarine mass failure (SMF) that occurred off of the U.S. East Coast sometime between 24 and 50 ka ago (Locat et al. 2009). While this slide occurred when the sea level was much lower than it is presently, which may have helped trigger the failure and caused a much different coastal impact of the generated tsunami, it can serve as a prototypical SMF along the east coast of North America. Following Locat et al. (2009), we also simulate a Currituck-like landslide using a composite of two slides (Table 2).

Here, we use NHWAVE to generate the SMF tsunami source on a $500 \mathrm{~m}$ grid, $400 \mathrm{~km}$ on a side (Fig. 8). For simplicity, no sponge layers are used on the edges of the domain, which will limit the meaningful time of computations before reflected waves propagate back into the domain. The bathymetry is obtained from the ETOPO1 data. The SMF motion is specified as a time dependent seabed deformation, assuming a translational slide, based on the center of mass motion equations of Grilli and Watts (2005). The slide is centered at $36.4 \mathrm{~N}, 74.5 \mathrm{~W}$, and moves due east. The initial acceleration is set to $5 \mathrm{~m} / \mathrm{s}^{2}$ and the terminal velocity to $10 \mathrm{~m} / \mathrm{s}$. The simulations are terminated at $t=$ $1150 \mathrm{~s}$ ( $\sim 19 \mathrm{~min})$ and the bottom friction coefficient is fixed at 0.0025, as in Geist et al. (2009).
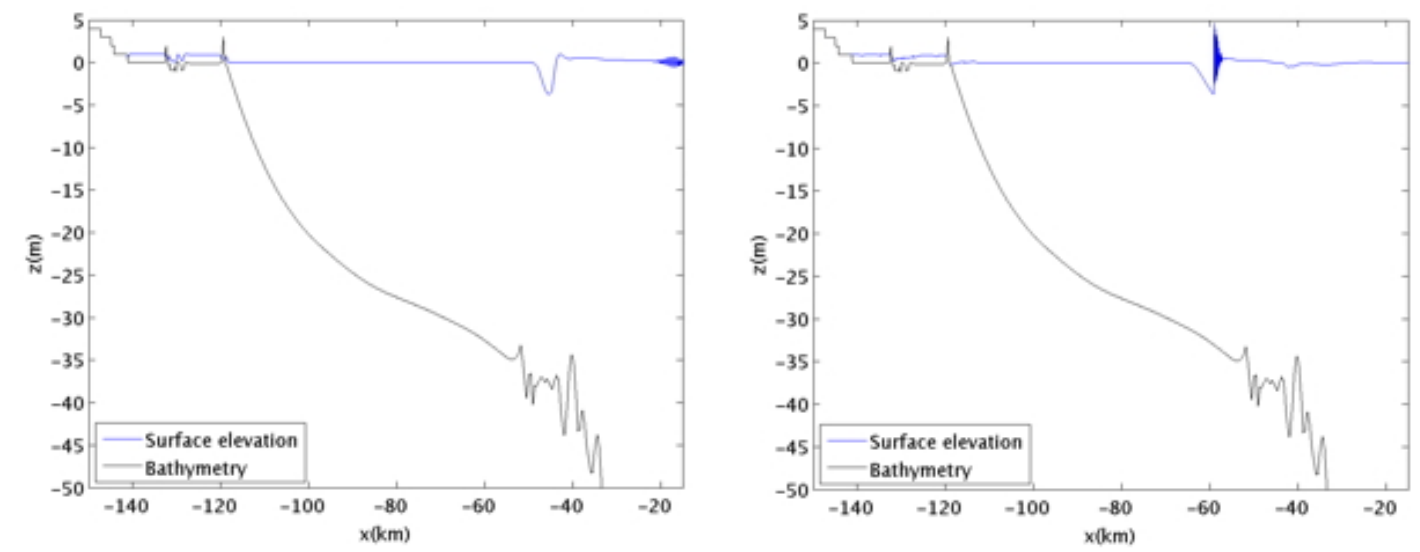

Figure 9. FUNWAVE-TVD simulation of the Currituck SMF tsunami in a 1D transect with a $10 \mathrm{~m}$ resolution mesh: interpolation of the initial surface elevation from NHWAVE (left panel); surface elevation after 14 min of simulations (right panel).
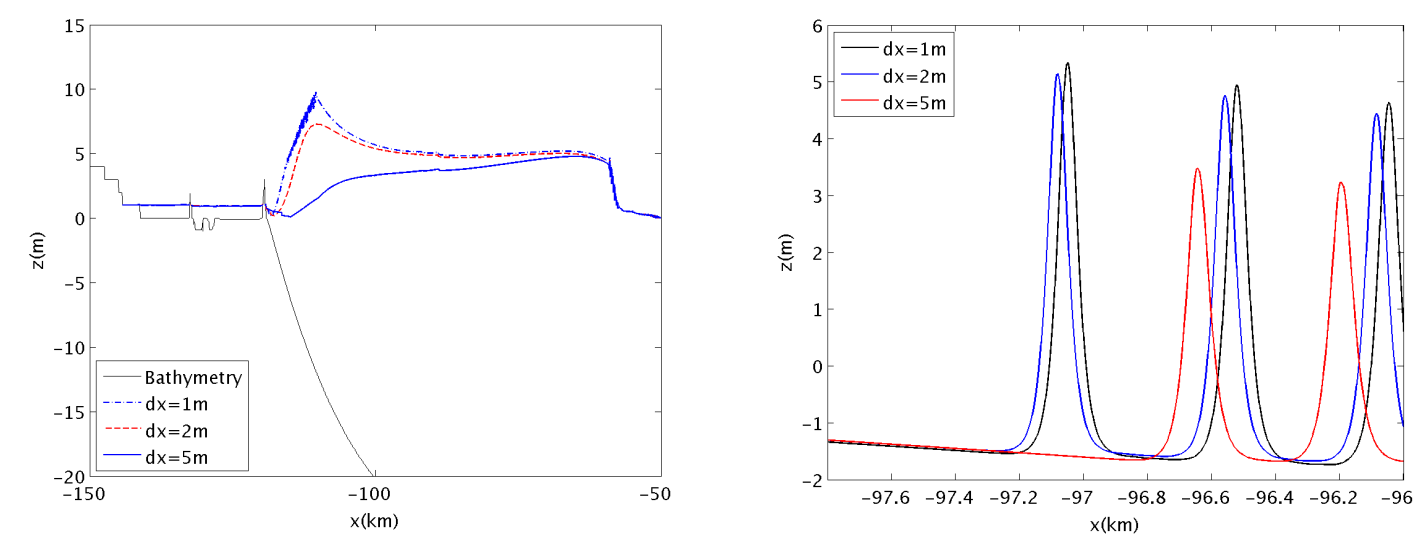

Figure 10. Same case as Fig. 9. Maximum surface elevation for different grid resolutions (left panel); close-up of surface elevation at $t=2,340 \mathrm{~s}(\sim 40 \mathrm{~min})$ for different grid resolutions (right panel). Note that even at a 1 $\mathrm{m}$ resolution, results do not seem to have been converged at the shoreline.

As the aim of this work is to model the effects of the landslide tsunami on the coast, the resolution needs to be much finer in the shallower water over the shelf. To do this in a computationally efficient 
manner and at the same time analyze the effects of mesh resolution on model results, as before, simulations are continued using FUNWAVE-TVD in a 1D transect. Here, the transect is located between $-150 \mathrm{~km}$ and $-15 \mathrm{~km}$ along the $x$-axis of Fig. 8 and computations are initialized, similar to the 1D transect work of the PNG tsunami, by interpolating NHWAVE results at $t=1,150 \mathrm{~s} \mathrm{(} 20 \mathrm{~min}$; Fig. 9). In the initial FUNWAVE-TVD simulation, a grid resolution of $10 \mathrm{~m}$ is used and the model is run for a 14 min duration, until the wave has propagated to shallower water (Fig. 9). Results are then reinterpolated onto even finer resolution grids to model the nearshore tsunami transformations. For these finest meshes, we consider a shorter domain, from $-150 \mathrm{~km}$ to $-50 \mathrm{~km}$ along the $x$-axis.

Fig. 10 compares results of model simulations performed using fine grids with 1,2 , and $5 \mathrm{~m}$ resolution. In the $5 \mathrm{~m}$ resolution grid, results appear similar to those of Geist et al. (2009); the appearance in the incident long waves of an undular bore made of soliton-like waves is quite clear, but wave dissipation is intense and occurs over a wide region $(\sim 50 \mathrm{~km})$. By contrast, at a higher resolution, waves continue to increase in height until they propagate much closer to shore. In all cases, however, dissipation due to breaking of the shorter waves reduces the coastal tsunami impact to small levels, unlike in Geist et al.'s results. Geist et al. for instance predict in their similar setup that there would be an inundation of over $5 \mathrm{~m}$ at the barrier island, whereas here the barrier island is barely inundated, but this may also be due to differences in the initial tsunami waves.

We know from the PNG tsunami simulations (which involved a much smaller slide volume) that a SMF can produce large runups along the coastline, so we could expect a large coastal impact in the Currituck case. This suggests that if the initial tsunami waves produced here are reasonable, too much dissipation may exist in the present model.

Finally, note that these simulations are along a coastline where there is a barrier island protecting the mainland. This may pose a special problem for tsunami hazard assessment. Because the wave period of a tsunami is so long that it may be possible for the first wave of a tsunami to wash away the top of any barrier island. As presently done here, however there is no model that would easily capture both the tsunami propagation and the short-term coastal morphology changes due to tsunami impact. Hence, a conservative estimate of tsunami hazard may be to recompute results assuming that no barrier island exists.

\section{SUMMARY AND PERSPECTIVES}

In this work, we reported on simulations of tsunami waves propagating over a wide shallow shelf, using a Boussinesq wave model, FUNWAVE-TVD. While FUNWAVE-TVD, like most operational tsunami models used for coastal hazard assessment, has been tested for many practical test cases, wave breaking is quite straightforward in most standard tsunami benchmarks. Breaking undular bores created as a result of the interplay of dispersive and nonlinear effects in incident long waves over shallow and mildly sloping continental shelves, however, are much more complicated.

While earlier tsunami hazard assessments from the far-field impact of the CVV tsunami (Harris et al. 2012) suggested that wave elevations would be quite high all along the US East Coast, the current results performed at higher resolution show a potentially different outcome. At a 7.5" resolution, the coastal impact appears to be predominantly determined by the magnitude of wave dissipation due to wave breaking. As this is contrary to existing understanding (e.g., Madsen et al. 2008), and because the tsunami hazard level is dominated by wave breaking, suitable benchmark cases are needed to verify whether such large decreases in tsunami wave height offshore are physically reasonable.

Breaking undular bores analogous to tsunamis have been experimentally studied over mild slopes by Matsuyama et al. (2007) in a wave flume. Our results showed that FUNWAVE-TVD is able to well reproduce the observed waveforms, including the process of undular bore formation and soliton fission. While some details of the flow do not match experiments as well, such as the maximum wave elevation at breaking, discrepancies found were also seen in the Boussinesq modeling conducted by Kim and Lynett (2011) for the same case. These results suggest that for such a leading elevation wave, the exact breaking model used may not be critical to simulating coastal impact. However, many tsunamis have leading-depression waves, resulting in a very different waveform nearshore. A classic example of a leading-depression tsunami would be that caused by most SMFs. Although SMFs were only recently recognized as a significant factor for tsunami hazard assessment, the Papua New Guinea tsunami of 1998 is now widely regarded to have been caused by a SMF. This tsunami was modeled by Tappin et al. (2008) using an earlier version of FUNWAVE. Revisiting these results with FUNWAVE-TVD has shown that a simple breaking model, such as that of Tonelli and Petti (2009), may not be sufficient for 
modeling the complex breaking phenomena occurring for the relatively shorter and more dispersive tsunami waves produced by a SMF. Simulations of a 1D transect with a BEM show that the breaking criterion based on the ratio of wave elevation to depth may not be accurate enough. Tests with a VOF model show that a Navier-Stokes model may have too much dissipation to provide a relevant benchmark solution.

Finally, we run simulations of a Currituck-like submarine landslide, similar to Geist et al. (2009). This corresponds to a realistic (though extreme) tsunami hazard off the US East Coast. We obtain similar results as Geist et al.'s with our $5 \mathrm{~m}$ resolution FUNWAVE-TVD simulations of a 1D transect, but we also find that the results do not converge to a unique solution when using finer resolution grids of 2 or $1 \mathrm{~m}$. For all cases, though, the use of the Tonelli and Petti (2009) breaking criterion reduces the coastal impact of dispersive SMF tsunami wave trains to quite low values. More comparisons with proper benchmarks are needed, however, to fully assess the relevance of the breaking model or proposed alternate models. Because of the weaknesses identified earlier on, a different breaking criterion, perhaps based on surface slope (e.g., Tissier et al. 2012) may be more appropriate.

Future work will continue the assessment and development of the breaking model to be used to simulate such cases in FUNWAVE-TVD. Interesting comparisons can also be made with the previous FUNWAVE versions based on finite-differences and the existing FUNWAVE-TVD to further understand the requirements needed to model the dissipation rates of leading-depression undular bores.

\section{ACKNOWLEDGEMENTS}

The first two and 5th and 6th authors wish to acknowledge support from grant EAR-09-11499/11466 of the US National Sciences Foundation (NSF) Geophysics Program. The $3^{\text {rd }}, 4^{\text {th }}$ and last authors acknowledge the Coastal Geosciences Program, Office of Naval Research for support for development of the FUNWAVE-TVD and NHWAVE models. All the authors acknowledge support from NOAANational Tsunami Hazard Mitigation program.

\section{REFERENCES}

Abadie S., C. Gandon, S.T. Grilli, R. Fabre, J. Riss, E. Tric, D. Morichon, and S. Glockner. 2009. 3D Numerical Simulations of Waves Generated by Subaerial Mass Failures. Application to La Palma Case. In Proc. 31st Intl. Coastal Engng. Conf. (J. Mc Kee Smith, ed.) (ICCE08, Hamburg, Germany, September, 2008), pps. 1,384-1,395. World Scientific Publishing Co. Pte. Ltd.

Abadie S., J. C. Harris and S.T. Grilli. 2011. Numerical simulation of tsunami generation by the potential flank collapse of the Cumbre Vieja Volcano. Proceedings of the $21^{\text {st }}$ Offshore and Polar Engng. Conf. (ISOPE11, Maui, HI, USA, June 19-24, 2011), 687-694.

Abadie S., J.C. Harris, S.T. Grilli, and R. Fabre. 2012. Numerical modeling of tsunami waves generated by the flank collapse of the Cumbre Vieja Volcano (La Palma, Canary Islands): tsunami source and near field effects. J. Geophys. Res., 117, C05030.

Chen Q., J.T. Kirby, R.A. Dalrymple, A. Kennedy, and A. Chawla. 2000. Boussinesq modeling of wave transformation, breaking and runup II: 2D. J. Waterway, Port, Coast. Oc. Engng., 126, 4856.

Enet F., and S.T. Grilli. 2007. Experimental study of tsunami generation by three-dimensional rigid underwater landslides. J. Waterway, Port, Coast. Oc. Engng., 133, 422-454.

Geist E., P. Lynett, and J. Chaytor. 2009. Hydrodynamic modeling of tsunamis from the Currituck landslide. Marine Geology, 264, 41-52.

Grilli S.T., J. Skourup, and I.A. Svendsen. 1989. An Efficient Boundary Element Method for Nonlinear Water Waves. Engineering Analysis with Boundary Elements, 6(2), 97-107.

Grilli S.T. and R. Subramanya. 1996. Numerical Modeling of Wave Breaking Induced by Fixed or Moving Boundaries. Computational Mech., 17(6), 374-391.

Grilli S.T. and P. Watts. 2005. Tsunami generation by submarine mass failure. Part I: Modeling, experimental validation, and sensitivity analysis. J. Waterway, Port, Coast. Oc. Engng., 131, 283297.

Grilli S.T., M. Ioualalen, J. Asavanant, F. Shi, J. Kirby, and P. Watts. 2007. Source Constraints and Model Simulation of the December 26, 2004 Indian Ocean Tsunami. J. Waterway, Port, Coast. Oc. Engng., 133(6), 414-428. 
Harris J.C., S.T. Grilli, S. Abadie, and T. Tajalli Bakhsh. 2012. Near- and far-field tsunami hazard from the potential flank collapse of the Cumbre Vieja Volcano. Proceedings of the $22^{\text {nd }}$ Offshore and Polar Engng. Conf. (ISOPE12, Rodos, Greece, June 17-22, 2012), 8 pp.

Ioualalen M., J. Asavanant, N. Kaewbanjak, S.T.Grilli, J.T. Kirby and P. Watts. 2007. Modeling the 26th December 2004 Indian Ocean tsunami: Case study of impact in Thailand. J. Geophys. Res., 112, C07024, doi:10.1029/2006JC003850

Kennedy A., Q. Chen, J.T. Kirby, and R.A. Dalrymple. 2000. Boussinesq modeling of wave transformation, breaking, and runup I: 1D. J. Waterway, Port, Coast. Oc. Engng., 126, 39-47.

Kim D.-H. and P. J. Lynett. 2011. Dispersive and non-hydrostatic pressure effects at the front of surge. J. Hydraulic Engng., 137, 754-765.

Kirby J.T., F. Shi, J.C. Harris, and S.T. Grilli. 2012. Sensitivity analysis of trans-oceanic tsunami propagation to dispersive and Coriolis effects. Ocean Modeling (in revision), $42 \mathrm{pp}$.

Locat J., H. Lee, U. ten Brink, D. Twichell, E. Geist, and M. Sansoucy. 2009. Geomorphology, stability, and mobility of the Currituck slide. Marine Geology, 264, 28-40.

Løvholt F., G. Pedersen, and G. Gisler 2008. Oceanic propagation of a potential tsunami from the La Palma Island. J. Geophys. Res., 113, C09026, doi:10.1029/2007JC004603.

Lynett P. and P.-F. Liu 2008. Modeling wave generation, evolution, and interaction with depthintegrated, dispersive wave equations COULWAVE code manual. Cornell University Long and Intermediate Wave Modeling Package.

Ma G., F. Shi, and J.T. Kirby. 2012. Shock-capturing non-hydrostatic model for fully dispersive surface wave processes. Ocean Modelling, 43-44, 22-35.

Madsen P.A., D.R. Fuhrman and H. A. Schaffer. 2008. On the solitary wave paradigm for tsunamis. J. Geophys. Res., 113, C12012, 22 pp.

Pérignon, Y. 2006. Tsunami hazard modeling, MSc thesis, Univ. of Rhode Island, Narragansett, RI.

Shi F., Q. Zhao, J.T. Kirby, D.S. Lee and S.N. Seo. 2004. Modeling of wave interaction with complex coastal structures using an enhanced VOF model. Proc. $29^{\text {th }}$ Intl. Conf. on Coastal Engng., 581593.

Shi F., J.T. Kirby, J.C. Harris, J.D. Geiman and S.T. Grilli. 2012. A High-Order Adaptive TimeStepping TVD Solver for Boussinesq Modeling of Breaking Waves and Coastal Inundation. Ocean Modeling, 43-44, 36-51, doi:10.1016/j.ocemod.2011.12.004.

Tappin D.T., P. Watts and S.T. Grilli. 2008. The Papua New Guinea tsunami of 1998: anatomy of a catastrophic event. Natural Hazards and Earth Syst. Sc., 8, 243-266.

Tehranirad B., F. Shi, J.T. Kirby, J. C. Harris, and S.T. Grilli. 2011. Tsunami benchmark results for fully nonlinear Boussinesq wave model FUNWAVE-TVD, Version 1.0. Technical report CACR11-02, Center for Applied Coastal Research, University of Delaware.

Tissier M., P. Bonneton, F. Marche, F. Chazel and D. Lannes. 2012. A new approach to handle wave breaking in fully non-linear Boussinesq models. Coastal Engng., 67, 54-66.

Tonelli M. and M. Petti. 2009. Hybrid finite volume - finite difference scheme for 2DH improved Boussinesq equations. Coastal Engng., 56, 609-620.

Ward S.N. and S. Day. 2001. Cumbre Vieja Volcano - potential collapse and tsunami at La Palma, Canary Islands. Geophys. Res. Lett., 21, 397-400.

Watts P., S.T. Grilli, J.T. Kirby, G.J. Fryer, and D. R. Tappin, 2003. Landslide tsunami case studies using a Boussinesq model and a fully nonlinear tsunami generation model. Natural Hazards and Earth Syst. Sc., 3, 391-402.

Watts P., S.T. Grilli, D. Tappin, and G.J. Fryer. 2005. Tsunami generation by submarine mass failure. Part II: Predictive equations and case studies. J. Waterway, Port, Coast. Oc. Engng., 131, 298310.

Wei G., and J.T. Kirby. 1995. A time-dependent numerical code for extended Boussinesq equation. $J$. Waterway, Port, Coast. Oc. Engng., 120, 251-261.

Wei G., J.T. Kirby, S.T. Grilli, and R. Subramanya, 1995. A Fully Nonlinear Boussinesq Model for Surface Waves. Part1. Highly Nonlinear Unsteady Waves. J. Fluid Mech., 294, 71-92. 